\title{
A segurança de barragens no Tocantins: implicações a partir das UHE, PCH e barragem de rejeitos
}

O Artigo pretende tecer considerações sobre a Segurança em Barragens no Estado do Tocantins, pela perspectiva da Defesa Civil. Os tipos de uso das barragens analisadas foram as que produzem energia elétrica (Usinas Hidrelétricas e Pequenas Centrais Elétricas) e as Barragens de Rejeitos. A pesquisa é um estudo exploratório que utiliza método indutivo alicerçado em uma revisão de literatura e pesquisa documental. Aspectos não explícitos na legislação que dizem respeito à responsabilidade dificultam a transição entre fase interna e fase externa, outro ponto é que os municípios onde existem esses empreendimentos ainda não possuem seus Planos de Contingência e muitos não possuem suas defesas civis constituídas, soma-se a isso, a necessidade da defesa civil estadual apoiar tecnicamente os municípios. Esse cenário representa as falhas de mercado que geram insegurança e abrem espaço para problemas como a disseminação de Fake News. Constatou-se a necessidade de criar um plano mais preciso de gestão e necessidade de melhoria na eficiência em segurança de barragens no Tocantins, além da necessidade de se estabelecer um gerenciamento voltado a atender de forma preventiva, mediante a promoção do monitoramento das estruturas e do sistema. Fortalecendo o discurso institucional e as práticas de defesa civil no Estado do Tocantins.

\section{Dam safety in Tocantins: implications from the HPP, SHP and tailings dam}

\begin{abstract}
The Article intends to make considerations about Safety in Dams in the State of Tocantins, from the perspective of Civil Defense. The types of use of the dams analyzed were those that produce electricity (Hydroelectric Plants and Small Power Plants) and Tailings Dams. The research is an exploratory study that uses an inductive method based on a literature review and documentary research. Non-explicit aspects in the legislation that concern liability hinder the transition between internal and external phases, another point is that the municipalities where these projects exist do not yet have their Contingency Plans and many do not have their civil defenses constituted, added to this, the need for the state civil defense to technically support the municipalities. This scenario represents market failures that generate insecurity and open space for problems such as the spread of Fake News. There was a need to create a more precise management plan and the need to improve efficiency in dam safety in Tocantins, in addition to the need to establish management aimed at providing preventive care, by promoting the monitoring of structures and the system. Strengthening institutional discourse and civil defense practices in the State of Tocantins.
\end{abstract}

Keywords: Dam Safety; Civil defense; Contingency plan.

Topic: Desenvolvimento, Sustentabilidade e Meio Ambiente

Reviewed anonymously in the process of blind peer
Received: 04/02/2021

Approved: 25/02/2021
Erisvaldo de Oliveira Alves

Universidade Federal do Tocantins, Brasil http://lattes.cnpq.br/1444539237263300 http://orcid.org/0000-0002-7608-0858 alvesbm12@gmail.com

Cristhyan Martins Castro Milazzo

Universidade Estadual de Goiás, Brasil http://lattes.cnpq.br/3293371046877451 chefiadegabinete@ueg.br
Referencing this:

ALVES, E. O.; MILAZZO, C. M. C.. A segurança de barragens no Tocantins: implicações a partir das UHE, PCH e barragem de rejeitos. Revista Ibero Americana de Ciências Ambientais, v.12, n.2, p.493505, 2021. DOI: http://doi.org/10.6008/CBPC21796858.2021 .002 .0042 


\section{INTRODUÇÃO}

Barragens podem ser entendidas como qualquer estrutura em um curso permanente ou temporário de água, que tem a finalidade de reter ou conter de forma acumulada substâncias líquidas ou de misturas de líquidos e sólidos. As barragens têm sido construídas há milhares de anos, sendo que, os primeiros registros remontam da época dos faraós no Egito, ao longo do Rio Nilo, e eram utilizadas para diminuir os efeitos das secas na região (FRANCO, 2008).

Ainda que importantes, não só para o abastecimento humano, mas para outros fins, como a geração de energia elétrica, esses empreendimentos possuem características que exigem cuidados para evitar acidentes, por isso, e pela gravidade dessas contingências, a segurança em barragens tem sido um tema debatido nacionalmente na atualidade.

De acordo com dados do Sistema Nacional de Informações sobre Segurança de Barragens - SNISB, gerido pela Agência Nacional de Águas - ANA, em 2018 constavam 19.280 barragens cadastradas no sistema (ANA, 2020). O Estado do Tocantins possui várias barragens, sendo o foco desse trabalho os empreendimentos de geração de energia e as barragens de resíduos sólidos, dado o potencial do desastre associado aos empreendimentos, já que, o rompimento dessas estruturas pode atingir cidades inteiras, exigindo preparação, não só do empreendedor, mas do poder público, o que obriga o Sistema de Defesa Civil a engendrasse para tal cenário.

Nesse entendimento, o Sistema Nacional de Defesa Civil deve cumprir o que prever Brasil (2012), lei de Defesa Civil, no tocante a apoiar, sempre que necessário, os municípios no levantamento das áreas de risco, missão da defesa civil estadual e, planejar as ações de enfrentamento desse tipo de desastre, no caso da defesa civil municipal, com a elaboração dos Planos de Contingência de Proteção e Defesa Civil - PlanCon, é imputado ainda às Coordenadorias Municipais de Proteção e Defesa Civil - COMPDEC, a divulgação de protocolos de prevenção e alerta de ações emergenciais.

O processo histórico de ocupação do Estado do Tocantins, o surgimento das instituições e os avanços em termos de infraestrutura, são fatos recentes, nesse interim encontra-se a situação da segurança das barragens no território estadual. Apesar de importante para o desenvolvimento socioeconômico, tais estruturas expõem a sociedade e o meio ambiente a riscos, uma vez que, acidentes com barragens produzem danos sociais, ambientais e, em alguns casos, perda de vidas humanas.

Atualmente não se tem uma preparação consolidada para resposta a esses desastres, nem por parte dos empreendimentos e nem do poder público, para o atendimento a acidentes que comprometam as populações que vivem na jusante das barragens. Isso implica em aumento da vulnerabilidade das populações, e exposição das mesmas a informações falsas, as denominadas Fake News.

A pesquisa busca analisar a segurança em barragem, não pelo viés dos órgãos fiscalizadores, já que a Defesa Civil não foi inserida no rol de instituições responsáveis pela fiscalização desses empreendimentos, mas pela ótica da resposta em situação de acidente ou não conformidade na segurança. Existe um limiar entre a responsabilidade do empreendedor e a responsabilidade do setor público em ocorrências envolvendo 
barragens. Uma transição entre a chamada fase interna e fase externa, que não está muito clara na legislação, necessitando um esforço no sentido de adequar os dois documentos de segurança, seja o Plano de Ação de Emergência - PAE, de responsabilidade do empreendedor e, o Plano de Contingência de Proteção e Defesa Civil - PlanCon, de responsabilidade da Defesa Civil do Município, além de diligenciar para que as execuções das ações sejam coordenadas de forma a cumprirem o que foi definido nos planos.

Sendo assim, este trabalho busca analisar o papel da Defesa Civil, no Estado do Tocantins, frente a essa discussão. Brasil (2010), na parte em que trata das competências, não relaciona a Defesa Civil como fiscalizador desse tipo de empreendimento, mas reconhece a importância do sistema de proteção ao definir que o Sistema Nacional de Defesa Civil (SINPDEC) deverá ser informado imediatamente de qualquer não conformidade que implique risco imediato à segurança ou qualquer acidente ocorrido nas barragens.

Posto isto, o artigo está dividido nessa introdução, a qual apresenta as linhas gerais do tema, o segundo item traz o referencial teórico sobre segurança de barragens, defesa civil e aspectos relevantes dessa interação, no terceiro item fica firmada a metodologia do trabalho e na quarta parte tem-se a discussão dos resultados encontrados sobre a situação da segurança de barragens no Estado e sugestões para a minimização dos riscos. Por fim, temos as considerações finais.

\section{DISCUSSÃO TEÓRICA}

\section{A segurança de barragens e a defesa civil}

As barragens podem ter diversos usos e finalidades de acordo com a necessidade da população da região, podem servir para a geração de energia, regularização de um rio, controle de enchentes e armazenamento de água. Este tipo de obra se tornou comum no mundo inteiro (FONTENELLE et al., 2018). Ao longo dos anos várias áreas situadas à jusante desses empreendimentos foram ocupadas por comunidades, muitas viraram cidades. Com isso, passa-se a existir um cenário de risco, pois essas populações podem ser atingidas em uma eventual ruptura da barragem ou mesmo durante sua operação, em casos de cheia eventual.

A segurança de uma barragem é garantida quando a estrutura se encontra preservada de quaisquer eventos e/ou mecanismos que possam contribuir para sua deterioração ou ruptura. O limiar que separa a situação de uma barragem como prevista em projeto daquela que implica riscos inaceitáveis para o empreendimento é a própria medida de sua segurança (MARTINI, 2018). Em uma concepção mais alarmista, Alves (2019) afirma que não só tem ocorrido o rompimento reiterado de barragens nos últimos anos no Brasil, mas que esses acontecimentos acarretaram elevados danos à vida, saúde, moradia, propriedade e ao meio ambiente equilibrado, direitos das populações atingidas pelos desastres.

Para que uma barragem seja inserida na Política Nacional de Segurança de Barragens, deve apresentar pelo menos uma das seguintes características: altura do maciço, contada do ponto mais baixo da fundação à crista, maior ou igual a 15m (quinze metros); capacidade do reservatório maior ou igual a $3.000 .000 \mathrm{~m}^{3}$; reservatório contendo resíduos perigosos conforme normas técnicas; categoria de dano 
potencial associado de grau médio ou alto, em termos econômicos, sociais, ambientais ou de perda de vidas humanas (MARTINI, 2018).

No mesmo sentido, Oliveira (2010) explica que a Resolução $n^{\circ} 144$ (CNRH, 2012) estabeleceu as diretrizes necessárias para a efetivação da Política Nacional de Segurança de Barragens e aplicação de seus instrumentos, além da criação e atuação do Sistema Nacional de Informações sobre Segurança de Barragens (SNISB). Definiu também os documentos necessários que devem compor o Plano de Segurança da Barragem, a ser elaborado pelo empreendedor para cada barramento específico, dentre os quais o PAE (ALVES, 2019).

$\mathrm{O}$ empreendedor deve produzir o $\mathrm{PAE}^{1}$, sendo que uma das informações mais importantes nesse documento são os mapas de inundação contendo os níveis d'água sobre o vale, seus tempos de permanência em cada área afetada, o tempo de chegada da vazão de pico e as velocidades do escoamento, para isso, é necessário estudar a extensão de uma possível onda de ruptura e delimitar as áreas potencialmente afetadas (VERÓL et al., 2012).

Viseu et al. (2011), assim como Franco (2008) reforçam que a avaliação das consequências reais que uma cheia induzida tem no vale a jusante, relacionam-se em termos de valor exposto ao risco, por pessoas, bens materiais e ambientais. Ou seja, relaciona-se com a vulnerabilidade do vale a jusante, dependendo de suas características intrínsecas do meio físico e, em particular, da população que nele reside.

Em outras palavras, "A vulnerabilidade hídrica de um evento crítico é a incapacidade do sistema (população ou ambiente) de retornar às condições prévias ao evento" (TUCCl et al., 2017). A vulnerabilidade pode estar associada ao meio físico, social, econômico, relacionando-se a fatores como: a capacidade de os edifícios resistirem ou não à cheia, a capacidade de sobrevivência dos indivíduos em risco e a capacidade de recuperação econômica pós-desastre, além do acesso à informação e sua compreensão. Outro ponto é que serve para testar os agentes de defesa civil e a população em risco na sua capacidade de anteciparem, agirem e recuperarem-se de um acidente. Entendida como capacidade de mitigação do risco externo ao empreendimento (VISEU et al., 2011).

A falha numa barragem pode causar danos materiais e ambientais, considerando, neste contexto, que tanto o ser humano quanto todos os demais seres vivos estão, aí, inseridos. A majoração dos valores dos cálculos da cheia máxima pode inviabilizar economicamente um projeto, entretanto, se os mesmos forem subdimensionados, poder-se-á verificar desastres. (FRANCO, 2008)

A gestão de segurança de um barramento deve ser planejada de modo a se ter uma clara definição da função de todos os participantes envolvidos. O planejamento deve ser conduzido com foco na identificação de todos os riscos e para atender primariamente o controle operacional, o controle de custos e o controle de documentos (OLIVEIRA, 2010).

Nas palavras de Martini (2018), a Lei 12.608/2012, designada de Brasil (2012) nesse trabalho, instituiu a Política Nacional de Proteção e Defesa Civil (PNPDEC) e deliberou sobre o Sistema Nacional de Proteção e Defesa Civil, alterando a nomenclatura do antigo Sistema Nacional de Defesa Civil (Sindec), que passou a designar-se por Sistema Nacional de Proteção e Defesa Civil (Sinpdec). O termo proteção, foi inserido para

${ }^{1}$ O Plano de Ação Emergencial -PAE contém os procedimentos e ações para garantir uma resposta eficaz às situações de emergência. Esse documento deve estar disponível no empreendimento e nas prefeituras envolvidas, além de ser encaminhado aos organismos de defesa civil (BRASIL, 2010). 
se adequar às normas internacionais de gestão de risco, tornando claro o caráter de prevenção que deve permear as ações do sistema, característica fundamental em Segurança de Barragens.

Segundo Brasil (2016) os Planos de Contingência Municipais para os riscos gerados por barragens, têm como foco atuar sob a área de impacto direto², em uma eventual situação de emergência. Esse documento seria o regulamento das ações na chamada fase externa, nessa fase procedimentos de caráter emergencial devem ser tomados pela população que se encontra na área de risco e pelo poder público local, ações típicas do Sistema de Proteção e Defesa Civil.

O esforço para reduzir ao máximo a chance de danos humanos em uma situação emergencial é o objetivo do Plano de Contingência nessas áreas. A distribuição das responsabilidades junto ao tema, consta na legislação relativa à Defesa Civil, sendo apresentadas as ações que competem ao órgão estadual, das quais: "apoiar, sempre que necessário, os municípios no levantamento das áreas de risco, na elaboração dos Planos de Contingência de Proteção e Defesa Civil e na divulgação de protocolos de prevenção e alerta de ações emergenciais" (BRASIL, 2012). Da mesma forma, consta a responsabilidade da defesa civil municipal, dentre as quais, destaca-se.

Art. 8o Compete aos Municípios:

[...] IV - Identificar e mapear as áreas de risco de desastres;

[...] VIII - Organizar e administrar abrigos provisórios para assistência à população em situação de desastre, em condições adequadas de higiene e segurança;

IX - Manter a população informada sobre áreas de risco e ocorrência de eventos extremos, bem como sobre protocolos de prevenção e alerta e sobre as ações emergenciais em circunstâncias de desastres;

[...] XI - Realizar regularmente exercícios simulados, conforme Plano de Contingência de Proteção e Defesa Civil;

XII - promover a coleta, a distribuição e o controle de suprimentos em situações de desastre;

[...] XVI - Prover solução de moradia temporária às famílias atingidas por desastres (BRASIL, 2012).

Brasil (2014) define os elementos que devem conter no Plano de Contingência Municipal, servindo como referência para a confecção desse documento, ainda que cada região tenha suas características próprias que devem ser consideradas. Os itens mínimos que devem conter no Plano de Contingência Municipal são: Indicação da responsabilidade de cada órgão, definição do sistema de alerta a desastres, organização dos exercícios simulados e do sistema de atendimento emergencial, definições das ações de atendimento médico-hospitalar e psicológico, cadastramento de voluntários e localização dos centros de distribuição de doações e suprimentos.

A preparação da população é necessária e tratasse de uma ação de mitigação de risco, sendo concretizada através de dois tipos de ações de responsabilidade da Defesa Civil, a primeiro trata da sensibilização da população, promovendo sessões de esclarecimento e divulgando informações relativas ao risco de habitar em vales a jusante de barragens, além de explicar o PAE e o Plano de Contingência; o segundo

\footnotetext{
2 Área de Impacto Direto: é o limite geográfico, gerado a partir de um estudo técnico especializado, que representa a área situada à jusante (à frente, ou abaixo) da barragem, e que pode vir a ser ATINGIDA caso haja uma ruptura do barramento (BRASIL, 2016).
} 
é em nível da educação e treino da população, para fazer face à eventualidade de uma cheia induzida, essa ação é direcionada à população da zona de risco, explicando a codificação dos significados das mensagens e as regras de evacuação, destacando nesse processo, a necessidade de realização dos exercícios simulados (VISEU, 2013).

\section{METODOLOGIA}

O trabalho é caracterizado como uma pesquisa exploratória, estruturada com uma revisão de literatura, utilizando informações de bancos de dados secundários, como relatórios e levantamentos institucionais. Apresenta-se como um estudo qualitativo, pois pode contribuir na identificação de fatores que atuam ou de alguma forma se relacionam com o problema da pesquisa. "As abordagens qualitativas de pesquisa se fundamentam numa perspectiva que concebe o conhecimento como um processo socialmente construído pelos sujeitos nas suas interações cotidianas, enquanto atuam na realidade, transformando-a e sendo por ela transformados" (ANDRÉ, 2019).

O método utilizado é o indutivo, já que ao selecionar um grupo de barragens: Hidrelétricas, Pequenas Centrais Elétricas e Barragem de Rejeitos; pretende-se, ao final, tecer considerações sobre a Segurança de Barragens no Estado e a relação da Defesa Civil nesse processo. O método indutivo, é aquele que parte do particular para o geral, percorrendo um conjunto de passos na direção de níveis de progressiva abstração, as observações empíricas conduzem a formulações potencialmente generalizáveis (CUNHA et al., 2019).

A amostra é formada por Usinas Hidrelétricas, Pequenas Centrais Elétricas e Barragem de Rejeitos que estão em operação no Estado, classificadas dentro dos critérios da PNSB e que a Coordenadoria Estadual de Proteção e Defesa Civil - CEPDEC possui informações, sendo o grupo definido pelos 12 (doze) respectivos empreendimentos: UHE - Peixe/Angical, UHE - Lajeado, UHE - São Salvador, UHE - Estreito, Barragem de Contenção de Rejeitos da Itafós, PCH - Manuel Alves, PCH - Água Limpa, PCH - Areia, PCH - Boa Sorte, PCH - Porto Franco, PCH - Riacho Preto, PCH - Isamu Ikeda.

Sobre a região pesquisada, tem-se que o Estado do Tocantins foi criado em 05 de outubro de 1988, possui uma área de $277.720,404 \mathrm{Km}^{2}$, tendo Palmas como sua capital. Limita-se ao norte com os Estados do Maranhão e do Pará; ao sul com o Estado de Goiás; ao leste com os Estados do Maranhão, do Piauí e da Bahia; e a oeste com os Estados do Pará e do Mato Grosso, possui 139 municípios. Ainda de acordo com o Censo Demográfico de 2010, o Estado do Tocantins possuía uma população de 1.383 .445 pessoas. A densidade demográfica é de 4,98 hab/ $/ \mathrm{km}^{2}$ (IBGE, 2020).

Segundo informações da defesa civil estadual (TOCANTINS, 2019), retiradas dos mapas de inundações constantes nos PAE enviados à CEPDEC, o Estado do Tocantins possui 24 (vinte e quatro) municípios que seriam afetados em situação de desastre envolvendo suas UHE, PCH ou Barragem de Rejeitos, apresentando como desafio a forma de melhorar a proteção das populações localizadas à jusante dessas barragens. Existem outros tipos de usos para os barramentos como irrigação, abastecimento humano, aquicultura, recreação, dessedentação animal, regulação de vazão, etc., e todos são importantes. Mas pesquisaremos as Barragens de Rejeitos, devido aos recentes acidentes com esse tipo de barramento, e as 
de geração de energia elétrica, pelo seu porte, e dano potencial associado a essas estruturas.

Para a elaboração do mapa coroplético, utilizado para georreferenciar, e facilitar a visualização das informações, localizando as áreas atingidas por eventuais desastres nesses empreendimentos, utilizou-se o Software QGIS, para tabulação dos dados foi utilizado a Planilha Eletrônica Excel.

\section{RESULTADOS E DISCUSSÃO}

\section{A Segurança de Barragens no Tocantins}

Para Viseu et al. (2011) cabe ao empreendedor, responsável primário pela segurança da barragem, o desenvolvimento das três primeiras fases numa situação de rompimento, definidas pelos autores como: Implantação de sistema de observação da barragem, sistemas de comunicação e instalação de sistema de alerta e alarme na Zona de Auto-Salvamento - ZAS. Cabendo à Defesa Civil local ser a responsável pelo aviso à população ao longo do vale a jusante e sua evacuação na chamada Zona de Salvamento Secundário - ZSS, juntamente com o empreendedor, que deve apoiar na evacuação. É imputado ainda à Coordenadoria Municipal de Proteção e Defesa Civil - COMPDEC, o desenvolvimento de ações de socorro e assistência, sensibilização e informações à população que reside na área de inundação. Por tanto, aduz pensar que a defesa civil local atua em todos os momentos do desastre, o que é coerente, diante da necessidade de coordenação ampla, mas isso não significa que seja responsabilidade do Estado, no sentido amplo, arcar com todos os custos dessas ações.

Apesar de Brasil (2010) não detalhar como se dará a transição da fase interna para a fase externa, tem-se necessidade da expertise da defesa civil durante toda a emergência, exigindo-se que ela acompanhe as ações nas ZAS, por isso a autoridade de defesa civil deve ter conhecimento do PAE, ainda que ele seja de responsabilidade do empreendedor. Porém, além disso, as ações realizadas na Zona de Segurança Secundária (Região de risco hidráulico, dificuldades de comunicação e dificuldades de acesso), de responsabilidade da COMPDEC, podem requerer a aplicação de recursos financeiros, materiais e humanos por vezes elevados, dependendo da magnitude da emergência e da dimensão da área de impacto, necessitando de aporte financeiro do empreendimento econômico que gerou a emergência.

A destruição provocada por uma cheia induzida pode obrigar à adoção de medidas que se estendam por centenas de quilômetros ao longo do vale a jusante. A preparação de respostas adequadas a este risco é essencial e garante que todos os recursos e serviços se encontrem operacionais e mobilizáveis quando necessários (VISEU, 2013).

Esse fato constitui um paradoxo frente à capacidade técnica e financeira dos municípios tocantinenses. Dessa forma, aduz pensar que há necessidade de apoio às ações de resposta aos municípios que podem vir a ser afetados pelo rompimento das barragens, e esse apoio compete ao empreendedor. Afinal, o desastre é gerado pela atividade econômica, e não parece razoável que medidas de enfrentamento sejam custeadas exclusivamente pelo poder público. Por tanto, Brasil (2010) tem o mérito de gerar os primeiros debates em segurança de barragens, mas existe uma grande oportunidade de melhoria no 
processo, ou seja, a discussão de forma a aumentar a ênfase nas ações emergenciais no caso de acidentes em barragens, essa abordagem pode conduzir a um ponto de equilíbrio entre necessidade de realização das ações e custo de sua execução, com definições claras de quem é o responsável financeiro.

Ainda que não tenhamos claro na legislação, essa responsabilidade pode ser percebia no Código Civil quando se tem:

Art. 927. Aquele que, por ato ilícito, causar dano a outrem, fica obrigado a repará-lo.

Parágrafo único. Haverá obrigação de reparar o dano, independentemente de culpa, nos casos especificados em lei, ou quando a atividade normalmente desenvolvida pelo autor do dano implicar, por sua natureza, risco para os direitos de outrem. (BRASIL, 2002)

Atualmente verifica-se uma tendência das empresas a preocuparem-se com a visão dos consumidores sobre sua política social e ambiental, por tanto, pode-se evocar o compromisso social do empreendedor - social commitment, ou ainda, buscar a aplicação da legislação ambiental ${ }^{3}$. O ideal é que essa discussão seja feita antes da situação emergencial, de preferência que fique clara nos planos e que gere os resultados esperados diante da situação concreta, qual seja, a minimização dos riscos de perda de vidas humanas.

Tratando sobre o PlanCon, o primeiro passo é que seja constituída a defesa civil municipal, através de decreto municipal e nomeação do coordenador municipal de proteção e defesa civil. Segundo CEPDEC (TOCANTINS, 2019), quase $17 \%$ dos municípios que podem ser impactados por desastres em barragens de UHE, PCH e Rejeitos, não possuem COMPDEC. A relação dos municípios e situação perante a Defesa Civil Estadual encontra-se no quadro 1.

Quadro 1: Municípios Impactados e as COMPDEC.

\begin{tabular}{|c|c|c|}
\hline Ord. & Cidade Afetada & COMPDEC \\
\hline 01 & Dianópolis & Sim \\
\hline 02 & Porto Alegre do Tocantins & Sim \\
\hline 03 & Novo Jardim & Sim \\
\hline 04 & Ponte Alta do Bom Jesus & Sim \\
\hline 05 & Taipas do Tocantins & Sim \\
\hline 06 & Miracema do Tocantins & Sim \\
\hline 07 & Tocantínia & Sim \\
\hline 08 & Pedro Afonso & Sim \\
\hline 09 & Rio dos Bois & Sim \\
\hline 10 & Tupirama & Sim \\
\hline 11 & Bom Jesus do Tocantins & Sim \\
\hline 12 & Lajeado & Sim \\
\hline 13 & Peixe & Sim \\
\hline 14 & São Valério da Natividade & Não \\
\hline 15 & Gurupi & Sim \\
\hline 16 & Aliança do Tocantins & Sim \\
\hline 17 & Ipueiras & Sim \\
\hline 18 & Brejinho de Nazaré & Não \\
\hline 19 & Porto Nacional & Sim \\
\hline 20 & Santa Rosa do Tocantins & Sim \\
\hline 21 & Palmas & Sim \\
\hline 22 & São Salvador & Não \\
\hline 23 & Arraias & Não \\
\hline 24 & Paranã & Sim \\
\hline
\end{tabular}

Fonte: Com base em Tocantins (2019).

\footnotetext{
${ }^{3}$ Art. 14 - [...] § 1ㅇ - Sem obstar a aplicação das penalidades previstas neste artigo, é o poluidor obrigado, independentemente da existência de culpa, a indenizar ou reparar os danos causados ao meio ambiente e a terceiros, afetados por sua atividade. O Ministério Público da União e dos Estados terá legitimidade para propor ação de responsabilidade civil e criminal, por danos causados ao meio ambiente (BRASIL, 1981).
} 
Outro dado relevante é que não consta nos registros da CEPDEC informações sobre Planos de Contingências Municipais (PlanCon), esse fato expõe a necessidade de preparação do poder público para atender a esse tipo de emergência. Sobre esse aspecto recai parte da responsabilidade sobre a Defesa Civil Estadual, haja vista a deficiência nos quadros técnicos dos municípios, cabendo ao órgão estadual prestar apoio específico. No entanto, os municípios são os principais responsáveis, já que a incumbência da elaboração do PlanCon é da Defesa Civil Municipal. O mapa 01 mostra os municípios que seriam impactados por um eventual rompimento dos empreendimentos de acordo com os PAE disponíveis na CEPDEC, não representando a mancha de inundação respectiva.

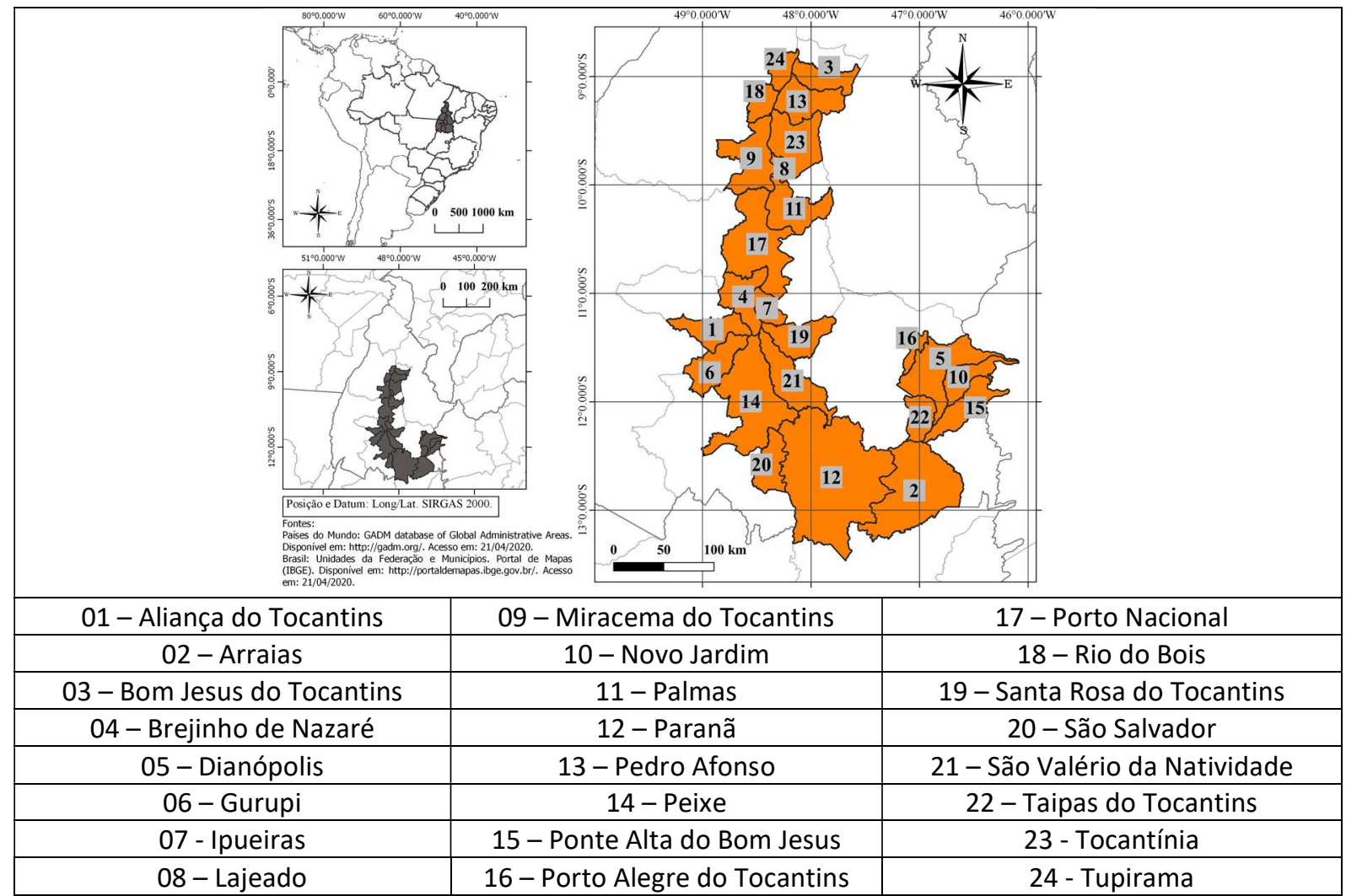

Figura 1: Municípios afetados em caso de rompimento das barragens. Fonte: Com base em Tocantins (2019).

Nesse contexto, a explicação que se apresenta é que não pode existir uma separação absoluta das ações da Defesa Civil e do Empreendedor, pois, se considerarmos que na chamada fase interna, gerida pelo PAE a responsabilidade das ações é do empreendedor, e que é notório a necessidade do apoio da defesa civil municipal nesse processo, já que, por exemplo, é inconcebível a efetiva retirada da população da ZAS sem a defesa civil local, tem-se, por outro lado, que na chamada fase externa as responsabilidades das ações recaem sobre o poder público através da defesa civil local, no entanto, só é possível realizar essas ações com o apoio do empreendedor, pelos motivos já expostos, principalmente no tocante a recursos financeiros.

Sobre o PAE, dos 12 (doze) empreendimentos analisados nesse estudo, apenas um (01) não entregou o seu Plano de Ação Emergencial à CEPDEC e 01 (um) apresentou com informações incompletas, necessitando detalhar melhor, o que foi solicitado pela Defesa Civil Estadual, sendo assim, aduz pensar que a parte documental da chamada Fase Interna está bem mais consistente que da Fase Externa.

A dicotomia (empreendedor versus defesa civil municipal) está presente nas duas fases. Logo, a falta 
de PAE também é responsabilidade do poder público que deve atuar de forma a corrigir as falhas de mercado, por outro lado, a não existência do PlanCon aduz pensar que não houve, solidariamente, empenho suficiente do empreendedor, por exemplo, se não houver um levantamento das informações eficientes de um mapa de inundação condizente com a realidade, não é possível a Defesa Civil Municipal prosseguir com a consecução da sua parte no processo.

\section{Falhas de Mercado e a Segurança de Barragens}

As barragens que se enquadram nos quesitos da Política Nacional de Segurança de Barragens, podem ter vários tipos de uso, dentre os quais, alguns são grandes empreendimentos econômicos, os quais estão sujeitos ao comportamento do processo de reprodução do capital, segundo Serpa (2019) a partir da década de 1990 o Brasil passou a delegar muitas de suas responsabilidades, passando a um modelo de Estado

Regulador. É por esse motivo que implementou o processo de regulação de algumas atividades econômicas, no caso específico a Agência Nacional de Energia Elétrica - ANEEL e Agência Nacional de Mineração - ANM, são as responsáveis pela fiscalização dos empreendimentos analisados.

Na prática, o Estado Regulador busca transferir competências de execução para a iniciativa privada por meio de (privatizações, concessões e terceirizações) ditando as diretrizes para tal execução, nesse feito, surge os conflitos que ocorrem em qualquer situação onde tenha-se a lógica de reprodução do capital, ou seja, a não alocação eficiente de recursos, as chamadas falhas de mercado, mas especificamente às externalidades ${ }^{4}$.

Em se tratando de Segurança de Barragens, esses conceitos econômicos foram traduzidos por Brasil (2010), para corrigir a externalidade negativa associada ao risco de perda de vidas humanas e destruição de patrimônio, causadas caso ocorra o rompimento dos barramentos. Dessa forma, pretende-se internalizar o custo da externalidade negativa ao empreendedor (ANA, 2017). Há também os riscos e incertezas que se referem ao desconhecimento por uma das partes em relação aos riscos de mercado, a inexistência de mobilidade adequada de recursos também é um dos fatores que geram distorção no equilíbrio desejável, sendo necessário uma regulação para minorar esses riscos e incertezas, como exemplo tem-se a assimetria de informações (NASCIMENTO, 2010).

Uma das falhas de mercado recorrentes em Segurança de Barragens é a Assimetria de Informação, que ocorre quando uma das partes tem maior informação do que a outra, como resultado, tem-se perda para a parte menos informada, "Portanto, ao detalhar os instrumentos da PNSB, a entidade fiscalizadora estará reduzindo as assimetrias de informação, permitindo uma alocação de recursos mais eficiente por parte dos empreendedores" (ANA, 2017).

Esse problema ocorre, por exemplo, quando o Plano de Segurança de Barragens, dentre outros documentos e informações, sejam de pouco conhecimento das entidades fiscalizadoras e do próprio Sistema

\footnotetext{
4 “O conceito de externalidade está ligado há uma ação econômica que gera efeitos indiretos (positivos ou negativos) sobre outros produtores ou consumidores" (SERPA, 2019).
} 
de Defesa Civil, sem falar na população que reside a jusante dos empreendimentos, o que gera diversas dúvidas e abre espaço para as chamadas Fake News, como a citada a seguir.

O Corpo de Bombeiros, por meio da Defesa Civil Estadual, informa que é fake News a gravação em áudio onde um suposto capitão faz alerta sobre ruptura de barragens de usinas hidrelétricas no Tocantins. A corporação não tem em seu quadro nenhum capitão por nome de Itamar Condussi, ou Conduci, e também desconhece que as barragens da região estejam com risco de ruptura.

A nota apresentada exemplifica a necessidade de uma informação simétrica sobre a real situação da segurança das barragens, para todos os atores envolvidos, inclusive para a população que reside na ZAS, isso é possível com a construção de um sistema de alerta e realização de simulados, haja vista, a facilidade de disseminação de notícias falsas e alarmistas, obrigando a Defesa Civil a emitir notas, que podem não atingir todos os interessados na mesma velocidade das Fake News. Por tanto, não basta o empreendimento cumprir todas as normas de segurança exigidas pelo órgão fiscalizador respectivo, é necessário que essa informação esteja disponível a todos e, mais ainda, que uma eventual não conformidade na segurança seja simetricamente informada aos atores, só assim, notícias falsas não serão consideradas e vários transtornos serão evitados, o que ainda não ocorre no Tocantins.

A crítica de Bizawu et al. (2017) é que na Política Nacional de Segurança de Barragem em seu artigo 170, inciso. VIII, 12.334/2010, está definido que cabe ao próprio empreendedor o dever de se automonitorar e lançar as informações sobre a segurança e estabilidade da barragem no Sistema Nacional de Informação de Barragem, essa situação seria um risco, haja vista que na maioria das vezes essas informações não são prestadas de acordo com a realidade da barragem, podendo ser mascaradas e não sendo conferida pelo ente público a veracidade das informações põe em risco a própria credibilidade da Política. Nesse caso o autor levanta uma situação de assimetria de informações que pode conduzir a uma externalidade negativa, justificando a discussão entorno das falhas de mercado.

As notícias falsas são efeitos indiretos, da falta de sincronismo entre os empreendedores e o poder público, necessitando maior clareza, para evitar situações onde a população fique exposta e apavorada, sendo bombardeada de informações falsas 'Circula nas redes sociais um vídeo onde mostra que um enorme volume de água escorre pelas comportas de uma usina hidrelétrica. A gravação foi atribuída à cidade de Peixe, região sul do Tocantins, mas se trata de uma \#FAKENEWS'. Utilizar notícias falsas sobre desastres em barragens para apavorar a população, pode não ser um fenômeno nacional, mas tem se mostrado fato recorrente no Estado do Tocantins.

Sendo assim, o reconhecimento dos possíveis danos em caso de acidentes com barramentos tornase uma exigência da população que reside a jusante do empreendimento, por tratar-se de fato relativo ao próprio cenário de risco à que esse grupo está sujeito pela existência do empreendimento econômico. "Numa sociedade de riscos a criação no imaginário coletivo de um estado de alerta permanente é medida de bom senso e que deve ser estimulada pelo Estado e pelo empreendedor da barragem" (ALVES, 2019).

Dentro do conceito de planejamento, é interessante evitar o estabelecimento de escolas a jusante de represas, notadamente nas ZAS. Esse raciocínio serve para localização de órgãos públicos, cinemas, teatros e outras áreas de concentração de pessoas. Havendo uma falha na estrutura do barramento, o dano 
e a destruição seriam potencialmente grandes. É necessário um apoio técnico aos municípios para que consigam produzir e executar os PlanCon e esse papel cabe à Defesa Civil Estadual, os empreendedores devem produzir seus PAE, aqueles que ainda não possuem. Se considerarmos o universo de empreendimentos que possuem, estes devem colocar o planejamento em prática, e ao município cabe assumir a dianteira desse processo, mesmo com todas as dificuldades postas.

O coroamento dessas ações é o simulado de evacuação da população afetada por um desastre em barragem, situação que ainda não foi registrada em nenhum dos casos apresentados à COMPDEC. Dessa forma, apresenta-se como razoável a hipótese da atividade econômica geradora de riscos, à população, também ser a geradora de mecanismos que busquem reduzi-los e mitigar seus efeitos numa situação emergencial e, que o poder público deve buscar minimizar as falhas de mercado, assumindo o papel de ator principal através da defesa civil municipal.

\section{CONCLUSÕES}

Por tanto, a segurança sugerida pela existência dos PAE (Fase Interna) e dos PlanCon (Fase Externa), necessitam de um processo de avaliação adequado para sua validação, garantindo que sejam periodicamente atualizados e que sejam realizados os exercícios simulados para verificação e correção de procedimentos referentes à eficácia dos alertas e da capacidade de evacuação a jusante dos empreendimentos, além de avaliar a capacidade de mobilização e coordenação do sistema de defesa civil no caso concreto.

Em eventos recentes de rompimento de barragens evidenciou-se que a magnitude de um desastre dessa natureza pode estar muito além da capacidade de resposta de um município e de sua Defesa Civil. Por isso, o empreendedor deve apoiar as ações seja evocando o Código Civil, a Legislação Ambiental ou o Social Commitment. As ações discutidas buscam minimizar as vítimas em ocorrências envolvendo barragens, sendo necessário estabelecer uma sistemática de forma a se criar e consolidar uma cultura de percepção do risco.

No Tocantins ainda há municípios que não possuem suas defesas civis estruturadas, há barragens que não possuem o PAE e todos os municípios tem dificuldade de executar as ações conforme prever a legislação de segurança de barragens. A segurança de barragens e todos os seus aspectos é um tema que está em construção no país, no Tocantins não é diferente, e avançará com a maior quantidade e disponibilidade de informações, produções acadêmicas e lições aprendidas de emergências dessa natureza.

\section{REFERÊNCIAS}

ANA. Agência Nacional de Águas. Manual de Políticas e Práticas de Segurança de Barragens para Entidades Fiscalizadoras. Brasília: ANA, 2017.

ANA. Agência Nacional de Águas. Sistema Nacional de Informações sobre Segurança de Barragens. Brasília: ANA, 2020.

ALVES, H. R.. O Estado de Coisas Inconstitucionais Face ao Reiterado Rompimento de Barragens no Brasil. Vertentes do Direito, v.6, n.2, p.131-157, 2019.

DOI: https://doi.org/10.20873/uft.2359-

0106.2019.v6n2.p131-157
ANDRÉ, M.. O que é um estudo de caso qualitativo em educação?. Revista da FAEEBA-Educação e

Contemporaneidade, v.22, n.40, p.95-103, 2019. DOI: https://doi.org/10.21879/faeeba23580194.2013.v22.n40.p95-103

BIZAWU, K.; MOREIRA, R. L.. Licenciamento Ambiental e a Política Nacional de Segurança de Barragem Lei 12.334/2010. Revista Jurídica - UNICURITIBA, v.3, n.48, p.271-298, 2017. DOI: http://dx.doi.org/10.6084/m9.figshare.5266342 
BRASIL. Lei n. 6.938, de 31 de agosto de 1981. Dispõe sobre a Política Nacional do Meio Ambiente. Brasília: DOU, 1981.

BRASIL. Lei n. 10.406, 10 de janeiro de 2002. Institui o Código Civil. Brasília: DOU, 2002.

BRASIL. Lei n. 12.334, de 20 de setembro de 2010. Estabelece a Política Nacional de Segurança de Barragens (PNSB) e cria o Sistema Nacional de Informações sobre Segurança de Barragens (SNISB). Brasília: DOU, 2010.

BRASIL. Lei n. 12.608, de 10 de abril de 2012. Institui a Política Nacional de Proteção e Defesa Civil (PNPDEC); dispõe sobre o Sistema Nacional de Proteção e Defesa Civil (Sinpdec) e o Conselho Nacional de Proteção e Defesa Civil (Conpdec). Brasília: DOU, 2012

BRASIL. Lei 12.983, de 2 de junho de 2014. Dispõe sobre as transferências de recursos da União aos órgãos e entidades dos Estados, Distrito Federal e Municípios para a execução de ações de prevenção em áreas de risco e de resposta e recuperação em áreas atingidas por desastres, dentre outros. Brasília: DOU, 2014.

BRASIL. Orientações para apoio à elaboração de Planos de Contingência Municipais para barragens. Brasília: MDR, 2016.

CNRH. Conselho Nacional de Recursos Hídricos. Resolução n. 144. Estabelece critérios gerais de classificação de barragens por categoria de risco, dano potencial associado e pelo volume do reservatório. Brasília: CNRH, 2012.

CUNHA, M. P.; REGO, A.. Métodos qualitativos nos estudos organizacionais e de gestão. Revista de Gestão dos Países de Língua Portuguesa, v.18, n.3, p.188-206, 2019. Dol: http://dx.doi.org/10.12660/rgplp.v18n3.2019.79780

FONTENELLE, M. C.; FONTENELLE, A. S.; MATOS, Y. M. P.; MONTEIRO, F. F.. Avaliação de risco em barragens: estudo de caso da barragem Malcozinhado do Nordeste Brasileiro. REEC-Revista Eletrônica de Engenharia Civil, v.14, n.1, p.2542, 2018. DOI: https://doi.org/10.5216/reec.v14i1.46356

FRANCO, C. S. S. P. A.. Segurança de Barragens: aspectos regulatórios. Dissertação (Mestrado em Engenharia do Meio Ambiente) - Universidade Federal de Goiás, Goiânia, 2008.
IBGE. Instituto Brasileiro de Geografia e Estatística. Território e Ambiente. IBGE, 2020.

MARTINI, B. D.. Sistema web para gestão de segurança de barragens. Dissertação (Mestrado em Geotécnica) Universidade Federal de Ouro Preto, Ouro Preto, 2018.

NASCIMENTO, E. R.. Gestão Pública. 2 ed. São Paulo: Saraiva, 2010.

OLIVEIRA, J. B. V. R.. Manual de operação de barragens de contenção de rejeitos como requisito essencial ao gerenciamento dos rejeitos e à segurança de barragens. Dissertação (Mestrado em Engenharia Geotécnica) Universidade Federal de Ouro Preto, Ouro Preto, 2010.

SERPA, R. V.. Uma visão multidisciplinar sobre a regulação no Brasil. Caderno de Direito e Políticas Públicas, v.1, n.1, 2019.

TOCANTINS. Coordenadoria Estadual de Proteção e Defesa Civil. Relatório da Defesa Civil Estadual do Tocantins. Palmas: CEPDEC/TO, 2019.

TUCCI, C. E. M.; CHAGAS, M. F.. Segurança hídrica: conceitos e estratégia para Minas Gerais. REGA, Porto Alegre, v.14, n.e12, p.1-16, 2017. DOI:

http://dx.doi.org/10.21168/rega.v14e12

VERÓL, A. P.; MIGUEZ, M. G.; MASCARENHAS, F. C. B..

Propagação da onda de ruptura de barragem através de um modelo Quasi-2D. Revista Brasileira de Recursos Hídricos, Rio de Janeiro, v.18, n.1, p.165-176, 2012. DOI: http://dx.doi.org/10.21168/rbrh.v18n1.p165-176

VISEU, T.; ALMEIDA, A. B.. Gestão do risco nos vales a jusante de barragens. Territorium, n.18, p.33-42, 2011. DOI: https://doi.org/10.14195/1647-7723 $18 \quad 3$

VISEU, M. T.. O risco e as barragens. In: MEDEIROS, W. D. A.. Riscos naturais, antrópicos e mistos. Homenagem ao Professor Doutor Fernando Rebelo. Coimbra: Universidade de Coimbra, 2013. p.425-440.

A CBPC - Companhia Brasileira de Produção Científica (CNPJ: 11.221.422/0001-03) detém os direitos materiais desta publicação. Os direitos referem-se à publicação do trabalho em qualquer parte do mundo, incluindo os direitos às renovações, expansões e disseminações da contribuição, bem como outros direitos subsidiários. Todos os trabalhos publicados eletronicamente poderão posteriormente ser publicados em coletâneas impressas sob coordenação da Sustenere Publishing, da Companhia Brasileira de Produção Científica e seus parceiros autorizados. Os (as) autores (as) preservam os direitos autorais, mas não têm permissão para a publicação da contribuição em outro meio, impresso ou digital, em português ou em tradução. 